\title{
Up-Goer Five Challenge: Cell counters for safe waters
}

Stefano Amalfitano ${ }^{1}$

${ }^{1}$ National Research Council of Italy (CNR)

April 18, 2018

Hundreds of very small and different cells may fit in a drop of water. They can appear as single cells and eventually form big cell groups. Apparently little is known so far on cell relationships and on how they respond to changes in surrounding water. This is because it is not easy to grow those tiny cells out of the place in which they live and it is not possible to recognize them by eye. My work is focused on studying new approaches to better understand how and how many cells can live or die in different waters (Amalfitano et al., 2017). Through so-called cell counters, we can find out the number and life state of cells. They can be colored, entire or in part, and forced one at a time to a point at which flashes of lights hit and turn them out blue, green, red. Within less than a minute, all color signs can be considered to figure out how many cell types are present in few water drops (figure 1). This approach is getting very important to settle in real-time if waters are safe for all possible human uses.

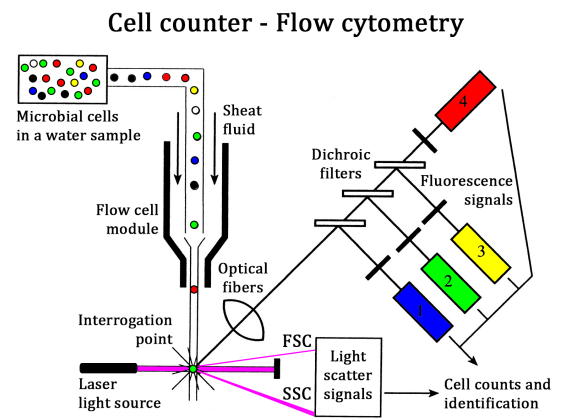

Figure 1: Overview of a cell counter or flow cytometer. The sheath fluid pushes microbial cells to pass through a laser beam one cell at a time. Forward (FSC) and side scatter (SSC) signals can be detected together with different fluorescence signals (i.e., blue, green, yellow, red) emitted from stained cells. 


\section{References}

Stefano Amalfitano, Stefano Fazi, Elisabet Ejarque, Anna Freixa, Anna M. Romaní, and Andrea Butturini. Deconvolution model to resolve cytometric microbial community patterns in flowing waters. Cytometry Part A, dec 2017. doi: 10.1002/cyto.a. 23304. URL https://doi.org/10.1002\%2Fcyto. a. 23304 . 